\title{
Optimization of laser-firing processes for silicon-heterojunction solar-cell back contacts
}

\author{
I. Sánchez-Aniorte ${ }^{\mathrm{a}, *}$, R. Barrio ${ }^{\mathrm{b}, 1}$, A. Casado ${ }^{\mathrm{b}}$, M. Morales $^{\mathrm{a}}$, J. Cárabe ${ }^{\mathrm{b}}$, \\ J.J. Gandía ${ }^{\mathrm{b}}, \mathrm{C}$. Molpeceres ${ }^{\mathrm{a}}$ \\ a Centro Láser UPM, Universidad Politếcnica de Madrid, Ctra. de Valencia Km 7.3, 28031 Madrid, Spain \\ ${ }^{b}$ Renewable Energy Division, CIEMAT. Av. Complutense, 22, 28040 Madrid, Spain
}

\begin{abstract}
A B S T R A C T
One of the key steps to achieve high efficiencies in amorphous/crystalline silicon photovoltaic structures is to design low-ohmic-resistance back contacts with good passivation in the rear part of the cell. A well known approach to achieve this goal is to use laser-fired contact (LFC) processes in which a metal layer is fired through the dielectric to define good contacts with the semiconductor. However, and despite the fact that this approach has demonstrated to be extremely successful, there is still enough room for process improvement with an appropriate optimization. In this paper, a study focused on the optimal adjustment of the irradiation parameters to produce laser-fired contacts in a-Si:H/c-Si heterojunction solar cells is presented. We used samples consisting of crystalline-silicon (c-Si) wafers together with a passivation layer of intrinsic hydrogenated amorphous silicon (a-Si:H(i)) deposited by plasma-enhanced chemical deposition (PECVD). Then, an aluminum layer was evaporated on both sides, the thickness of this layer varied from 0.2 to $1 \mu \mathrm{m}$ in order to identify the optimal amount of $\mathrm{Al}$ required to create an appropriate contact. A q-switched $\mathrm{Nd}: \mathrm{YVO}_{4}$ laser source, $\lambda=532 \mathrm{~nm}$, was used to locally fire the aluminum through the thin a-Si:H(i)-layers to form the LFC. The effects of laser fluences were analyzed using a comprehensive morphological and electrical characterization.
\end{abstract}

Keywords:

Laser firing

Laser processing

Heterojunction

Solar cell

Surface treatment

\section{Introduction}

An efficient strategy for minimizing recombination losses of solar cells is to reduce the metal-semiconductor interface area at the contacts and passivating the remaining surface area by dielectric layers [1]. Point contacts reduce the influence of recombination in the heavily diffused contact regions by limiting their total area. This has traditionally been achieved using expensive photolithographic processing steps. Also, for obtaining low-cost and highly efficient solar cells, it is crucial to use a reliable technology for realising openings in passivating layers without damaging the underlying silicon.

An example of this strategy is the rear side Laser Fired Contact (LFC), a technique introduced by the Fraunhofer Institute for Solar Energy Systems $[2,3]$ which presents a promising way to reduce the recombination associated with the rear electrode. In Laser-Fired Contact (LFC) an array of low energy laser pulses is used to alloy the aluminum layer to the bulk in localized regions in such a way that it is possible to form rear point contacts.

This paper discusses the mechanism of a Laser Fired technique for re-establishing rear connections in photovoltaic solar cells. Specifically, the work presented investigates the application of advanced laser processing to improve the back contact of siliconheterojunction (SHJ) solar cells.

\section{Experimental}

The experiments were performed on aluminum/a-Si:H(i)/c$\mathrm{Si}$ structures with $\mathrm{c}-\mathrm{Si}$ based on $\langle 100\rangle$ p-type float-zone monocrystalline-silicon wafers (resistivity range $1-5 \Omega \mathrm{cm}$, thickness $300 \mu \mathrm{m}$ ). Plasma-deposited intrinsic hydrogenated amorphous silicon layer (a-Si:H(i)) by 13.56-MHz PECVD was used as the passivating rear layer. This dielectric layers had a thickness of $80 \mathrm{~nm}$. Finally aluminum (Al) layer of different thicknesses $(0.2$, $0.4,0.6,0.8$ and $1 \mu \mathrm{m}$ ) was evaporated by thermal evaporation in a vacuum atmosphere at ambient temperature. The samples were rotated at uniform speed during the evaporation in order to obtain homogenous Al-contacts.

In order to evaluate the electrical performance of the LFC, a structure with isolated areas was prepared. In each remote area of 


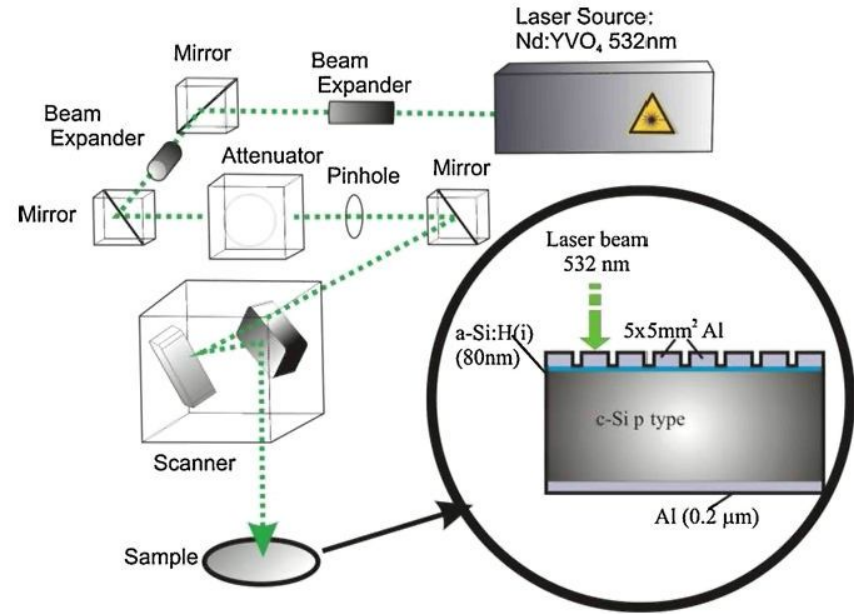

Fig. 1. Sketch of a laser scanner head for micro machining. Inset: expanded view illustrating the sample structure. The contact pattern (dots) is laser-fired and melting the aluminum locally through the dielectric layer.

$5 \mathrm{~mm} \times 5 \mathrm{~mm}$ covered with Al layers of various thicknesses (while a metallic Al film in the opposite side of the wafer remain with a constant thickness of $\sim 0.2 \mu \mathrm{m}$ ) a unique $\mathrm{LFC}$ point was performed. Then, current-voltage characteristics $(I-V)$ of the samples were measured to obtain the resistance of each area contacted.

The laser equipment consisted of a nanosecond Q-switch $\mathrm{Nd}: \mathrm{YVO}_{4}$ laser (Spectra Physics Explorer), operating at $532 \mathrm{~nm}$ with short pulse durations ( $\tau$ pulse-15ns) in TEM $_{00}$ operation mode. The repetition frequency was fixed at $20 \mathrm{kHz}$. The laser light was directed through a galvanometric scanner with a lens of focal length $250 \mathrm{~mm}$ onto the sample under investigation (see Fig. 1). The optical system defined a spot size of $15 \mu \mathrm{m}$ radius on the sample. The number of pulses used in the process was controlled by means of an electro-mechanical shutter.

The morphological characterization was performed by using a scanning electron microscope (SEM) Hitachi S-3000N, and depth profile of holes was made using a white light optical confocal microscope Leica DCM3D. In order to get an additional insight into the structural properties, Energy Dispersive X-ray (EDX) mapping was carried out. EDX technique gives an excellent inside on microstructures arrangement in terms of both chemistry and morphology environment. Finally, all data was analyzed to determine best laser conditions to obtain good ohmic contacts.

\section{Results and discussion}

\subsection{Morphological analysis}

The fundamental understanding of both structural changes within the altered surface layer as well as in-diffusion of $\mathrm{Al}$ into the
LFC is essential for the technological optimization of the contact properties. The interaction study was determined by SEM observations of the laser-produced craters. Typical craters obtained with nanosecond laser pulses are shown in Fig. 2. It is testified that some debris resembling of frozen droplets remain on the metal surface. This feature is a signature of the strong thermal character of the laser irradiation.

Fig. 2 shows the SEM images of irradiated areas for laser fluencies of 11.3 and $1.5 \mathrm{~J} / \mathrm{cm}^{2}$. Micrographs reveals that the inner and outer rings of the craters have an energy dependence, when the laser beam strikes the surface the material was etched away with a geometry that is defined by the light beam and it can be seen clearly that the diameter increases with increase impulse energy. It was evident that the laser melts the surface layer of the semiconductor. Image in Fig. 2 shows a typical melting texture with droplets in the immediate proximity because of rapid heating and cooling. A possible explanation for the contact formation is that the power of the laser is shallow absorbed, the silicon is molten and the passivating layer was lifted off during the expansion. Similarly to Platakis et al. [4].

The interaction between laser and material was studied by varying the $\mathrm{Al}$ layer thickness $(0.2,0.4,0.6,0.8$ and $1 \mu \mathrm{m})$; the various metal thicknesses used were intended to provide a wide variety of working conditions for the laser-induced connection process. From confocal inspection, reported in Fig. 3, it is patent that higher power values correspond to deeper crater and greater hole diameter formation, while lower power values leave the superficial morphology less modified and reduce the laser induced damages in the crystalline Si bulk.

To further investigate the morphology of laser fired process, the hole profile cross section was measured by confocal, as shown in Fig. 3. The figure exhibit the Al layer in blue color and the $\mathrm{Si}$ is in grey color, confirming that the passivating layer is removed.

Color-Scan mapping and element imaging were means to detect heterogeneous samples respectively to find phases and suitable spots for analysis. Fig. 4 shows a colored EDX mapping. Fig. 4a represents two-dimensional concentration distribution of an element over the sample surface, in which it is easy to distinguish the silicon concentration (colored in green) and the aluminum concentration (red). Fig. $4 \mathrm{~b}$ represents a color-mapping and a multipoint analysis that measures mean concentrations across the hole transverse section. As guide-to-the-eye a different colored circle is shown and represents areas with distinct aluminum concentrations. It is clear that the statistical concentration of elements follows an axial distribution.

A possible explanation of development contacts on $\mathrm{Al} / \mathrm{a}$ $\mathrm{Si}: \mathrm{H}(\mathrm{i}) / \mathrm{Si}$ layers is the following: the Al layer on passivated $\mathrm{C}-\mathrm{Si}$ wafer is heated with two or more laser pulses, there is a drilling process through the metallic film. The local heating causes thermal and mechanical stresses which fracture the a-Si:H layer. Subsequent pulses eject the molten silicon which on cooling forms a continuous layer covering the entire inner surface hole through the metal


Fig. 2. SEM pictures of LFC in Al/a-Si:H(i)/c-Si craters processed with different laser power $11.3 \mathrm{~J} / \mathrm{cm}^{2}, 2.8 \mathrm{~J} / \mathrm{cm}^{2}$, and $1.55 \mathrm{~J} / \mathrm{cm}^{2}$ at $20 \mathrm{kHz}, \mathrm{N}=2 \mathrm{pulses}$ per point. The Al thickness was $0.4 \mu \mathrm{m}$ 

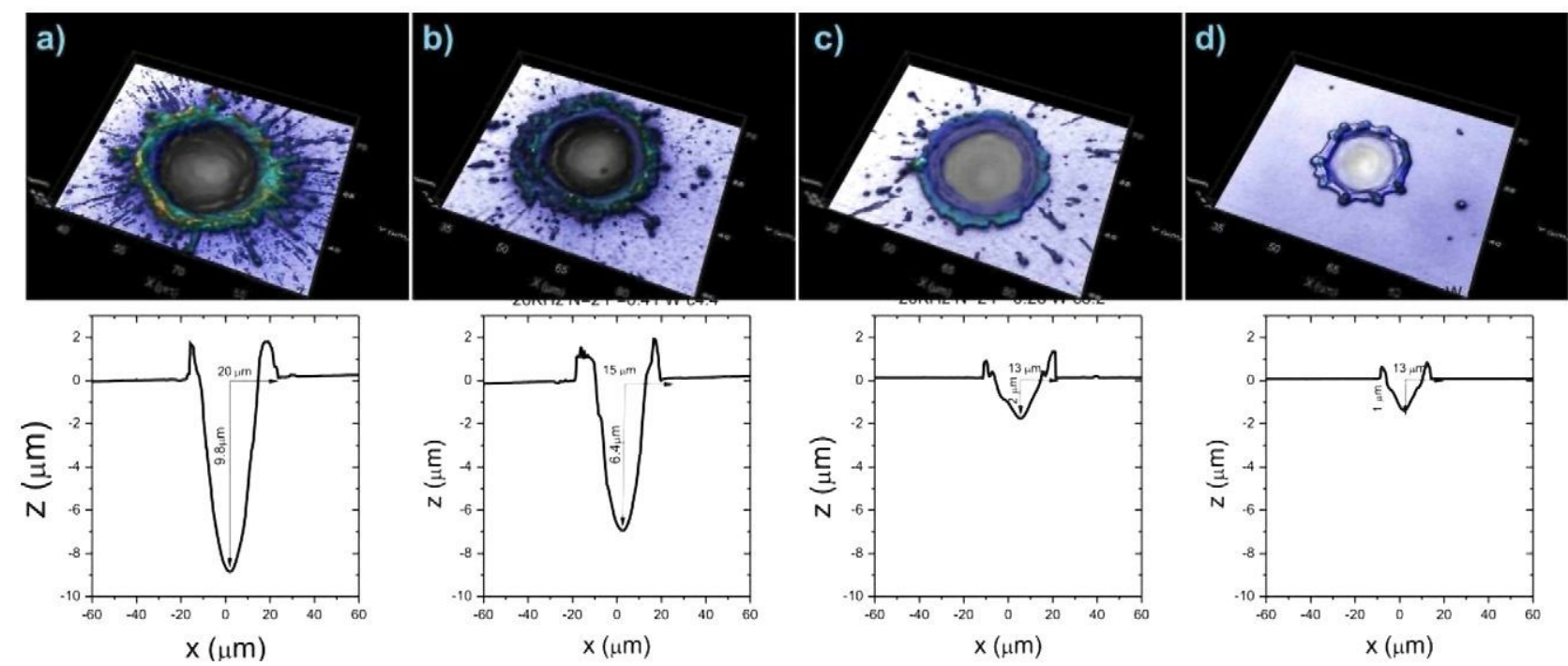

Fig. 3. Confocal transverse section across the irradiation zone in a sample with $0.4 \mu \mathrm{m} A$ thicknesses processed with different laser power. The variation in power from the left to right side is illustrated by: (a) $11.3 \mathrm{~J} / \mathrm{cm}^{2}$, (b) $5.7 \mathrm{~J} / \mathrm{cm}^{2}$, (c) $2.8 \mathrm{~J} / \mathrm{cm}^{2}$ and (d) $1.55 \mathrm{~J} / \mathrm{cm}^{2}$ at $20 \mathrm{kHz}, 2$ pulses per point.

and the passivating layer. It is believed that final electrical contact to the Al layers occurs when molten Si flows from the Si wafer to coat the inside hole [6]. Once the melted area has cooled down an Al/Si alloy is formed [4] and stabilises a conducting path between the substrate and the metal.

Fig. 5 shows the Al concentration diffused inside the LFC craters for different Al layer thickness. Results reveal there is an optimal laser fluence for an $\mathrm{Al}$ thickness in which the presence of $\mathrm{Al}$ inside the crater is the highest $\left(1.2 \mathrm{~J} / \mathrm{cm}^{2}\right)$, so the higher content of aluminum atoms the thinner metal layers $(0.2 \mu \mathrm{m})$. This is a competitive advantage for manufacturing devices in terms of using less material for the creation of rear contacts.

Pulsed laser remelting under the proper conditions produces regrown layers with higher concentration of $\mathrm{Al}$, this situation may be beneficial to the local contact formation due to the high Al-atom concentration in the contacted zone.

\subsection{Electrical characterization}

The resulting micro-connections were checked by measuring the contact resistance $R_{L F C}$ between the metallic film of each individual single IFC point, and the rear homogeneous Al layer of $\sim 0.2 \mu \mathrm{m}$. The resistance of a LFC contact $R_{L F C}$ can be calculated as the sum of three terms, namely the spreading resistance $\left(R_{S P}\right)$, the laser-fired contact resistance $\left(R_{C}\right)$ and the back resistance in the opposite Si-Al contact $\left(R_{m}\right)$ [7]:

$R_{L F C}=R_{m}+R_{s p}+R_{c}=R_{m}+\frac{\rho_{b}}{4 r}+\frac{r_{c}}{\pi r^{2}}$, where $\rho_{b}$ is the resistivity of the wafer, $r$ is the radius of the crater and $r_{c}$ the specific contact resistance of the laser fired contact. The $\boldsymbol{R}_{\boldsymbol{m}}$ term is three orders of magnitude lower and therefore negligible. We can normalize the LFC resistance $R_{L F C}$ considering the spot area by means of the specific LFC resistance $r_{L F C}$ in $\Omega \mathrm{cm}^{2}$ units [8]:

$r_{L F C}=R_{L F C} \times \pi r^{2}$.

Thus in order to evaluate the quality of the laser processes to create a LFC, the specific contact resistance was calculated using the following expression:

$r_{c} \approx r_{L F C}-\pi r \frac{\rho_{b}}{4}$.

In order to evaluate the contact resistance, the $r$ parameter was taken as the average value obtained from the outer radii (see Fig. 2) because it is believed that the real contact is in the border of the crater $[3,5]$.

Preliminary results are shown in Fig. 6. In this case specific LFC resistance yields a minimum of $0.5 \mathrm{~m} \Omega \mathrm{cm}^{2}$ with only two pulses per contact with an Al layer of $0.2 \mu \mathrm{m}$ thickness. $0.4 \mu \mathrm{m}$ Al thickness this value is about $1.4 \pm 0.1 \mathrm{~m} \Omega \mathrm{cm}^{2}$.

Table 1 summarizes the optimal laser conditions for every Al layer thickness, the $\mathrm{LF}$ specific contact resistance $r_{c}$ and $\mathrm{Al}$ concentration in the center of the laser contact. The number of shut/spot is kept constant to only two pulses per contact. Comparing Table 1 and Fig. 6 it can see that lower laser fluencies conditions in thinner Al layer $(0.2 \mu \mathrm{m})$ yields between twice and four times lower $r_{c}$ resistances than laser process at higher $\mathrm{Al}$ thicknesses.



Fig. 4. (a) EDX element composition mapping in green color correspond with the presence of Si and red color is assigned to the presence of $A \mathrm{l}$ ( $0.4 \mu \mathrm{m}$ thickness) (b) shows an EDX mapping of a transverse profile contact. (For interpretation of the references to color in this figure legend, the reader is referred to the web version of the article.) 


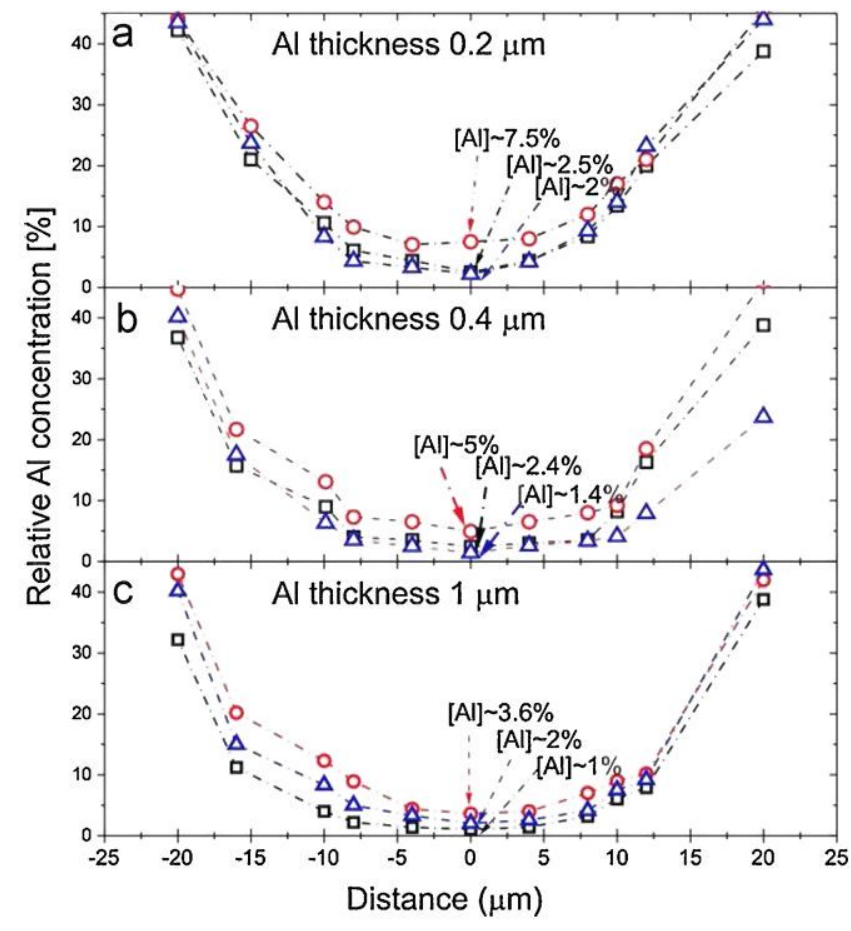

Fig. 5. Al concentration measured across laser-craters: (a) with $0.2 \mu \mathrm{m}$, (b) $0.4 \mu \mathrm{m}$ and (c) $1 \mu \mathrm{m} \mathrm{Al}$ thickness. The black profile corresponds to a laser fluences of $11.3 \mathrm{~J} / \mathrm{cm}^{2}$, the blue one to $5.7 \mathrm{~J} / \mathrm{cm}^{2}$ and the red to $1.55 \mathrm{~J} / \mathrm{cm}^{2}$. (For interpretation of the references to color in this figure legend, the reader is referred to the web version of the article.)

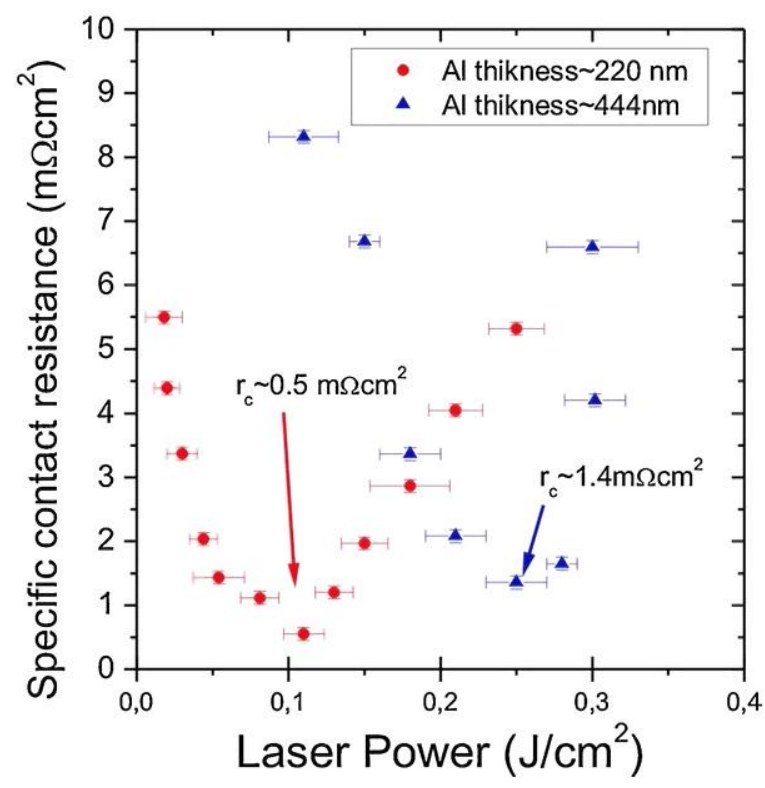

Fig. 6. Specific contact resistance behaviour when using different laser power and Al thicknesses.

Is important to remark that for each $\mathbf{A l}$ layer thickness there is optimal laser fluence for which specific contact resistance $r_{c}$ $\left(\mathrm{m} \Omega \mathrm{cm}^{2}\right)$ is minimum and $\mathrm{Al}$ concentration inside the hole is
Table 1

Quality parameters concerning the melting of Al layer with different thickness exposed to $532 \mathrm{~nm}$ laser radiation. The minimum contact resistance reveals the optimal laser parameter to achieve a good ohmic contact.

\begin{tabular}{llll}
\hline $\begin{array}{l}\text { Thickness Al } \\
\text { layer }(\mu \mathrm{m})\end{array}$ & $\Phi_{\text {optimal }}\left(\mathrm{J} / \mathrm{cm}^{2}\right)$ & $\tau_{C}\left(\mathrm{~m} \Omega \mathrm{cm}^{2}\right) \pm 0.1 \%$ & {$[\mathrm{Al}] \% \pm 1 \%$ center } \\
\hline 0.2 & $1.20 \pm 0.01$ & 0.5 & 7.5 \\
0.4 & $1.55 \pm 0.01$ & 1.4 & 5.0 \\
0.6 & $2.00 \pm 0.02$ & 1.9 & 5.0 \\
0.8 & $2.30 \pm 0.01$ & 2.2 & 4.0 \\
1.0 & $2.30 \pm 0.03$ & 2.4 & 3.6 \\
\hline
\end{tabular}

maximum. This behaviour was explained due to higher Al thickness implies increasing laser fluencies to make $\mathrm{Al} / \mathrm{c}-\mathrm{Si}$ contact. This led to a greater surface temperature and the aluminum evaporation temperature was exceeded, therefore fewer aluminum atoms were penetrated or diffused into the semiconductor and the measured Al concentration is lower.

\section{Conclusions}

In view of these results, laser appears to be a powerful tool for creating local contact openings after the conventional cell processing. It has been shown that micro connections can be formed between aluminum and diffused silicon layers in siliconheterojunction (SHJ) solar cells, in which the aluminum and the silicon were separated by a intrinsic hydrogenated amorphous silicon (a-Si:H(i)) layer.

It is found that for laser power between 0.1 and $0.4 \mathrm{~W}$ (fluences $1.4-5.7 \mathrm{~J} / \mathrm{cm}^{2}$ ) satisfactory $r_{L F C}$ values (less than $1 \mathrm{~m} \Omega \mathrm{cm}^{2}$ ) can be obtained with 2 shots/spot. Thus processes with at least two pulses can be assured to form good contact aluminum. It is important to remark that the best electrical results are obtained with thin layers of aluminum $(0.2 \mu \mathrm{m})$, achieving the excellent low specific contact resistance values of $0.5 \mathrm{~m} \Omega \mathrm{cm}^{2}$.

Further investigation, including dopant concentration as a function of depth, composition and microstructural analysis should be considered to fully understand these results.

\section{Acknowledgements}

Work supported by Spanish MICINN Projects PSE-MICROSIL08 (PSE-12000-2008-1) and INNDISOL (IPT-4200-2010-6) financed by FEDR (UE) "Una manera de hacer Europa".

\section{References}

[1] A. Grohe, C. Harmel, A. Knorz, S.W. Glunz, R. Preu, Prog. Photovoltaics Res. Appl. 17 (2 (March)) (2009) 101-154.

[2] D.-H. Neuhaus, A Münzer, 24521, 15 pages, 2007. doi:10.1155/2007/24521.

[3] E. Schneiderlöchner, R. Preu, R Lüdemann, S.W. Glunz, Prog. Photovolt. Res Appl. $10(2002) 29-34$

[4] .N.S. PLatakis, J. Appl. Phys. 47 (1976) 2120.

[5] I. Sánchez-Anjorte, M. Colina, F. Perales, C. Molpeceres, Physics Procedia 5 (2010) 285-292, doi:10.1016/j.phpro.2010.08.148.

[6] Sachin Bet, Nathaniel Quick, Aravinda Kar, Acta Mater. 55 (2007) 6816-6824.

[7] P. Ortega, A. Orpella, I. Martín, M. Colina, G. López, C. Voz, M.I. Sánchez, C. Molpeceres, R. Alcubilla, Prog. Photovolt: Res. Appl. (2011), doi:10.1002/pip.1115.

[8] P. Ortega, A. Orpella, G. Lopez, I. Martín, C. Vozl, R. Alcubilla, I. SánchezAniorte, M. Colina, C. Molpeceres, F. Perales, Proc. EU PVSEC. doi: 10.4229/25thEUPVSEC2010-2CV.3.16. 